\title{
11 Assessing the Quality of European Democracy Are Voters Voting Correctly?
}

\author{
Martin Rosema and Catherine E. de Vries
}

\subsection{Introduction}

DURING THE LAST TWO DECADES THE PROCESS OF EUROPEAN INTEGRATION has undergone important changes. Whereas until the early I990s the integration process was widely seen as an elite-driven project in which public opinion was largely irrelevant, today there is increasing evidence to suggest that issues relating to European integration are shifting from the realm of elite politics to that of mass politics. Major European initiatives, such as the creation of the common currency, influence the everyday lives of citizens throughout Europe. In addition, many of the major treaties sparked off popular interest through contentious referendum campaigns - to date only six out of the current 27 member states of the European Union have not (yet) held a referendum on matters relating to the European project. Consequently, it is safe to say that European issues have reached the contentious world of popular referenda and electoral politics, and that citizens are increasingly aware of the ramifications of the process (Hooghe and Marks 2008).

Against this backdrop, the debate regarding the lack of accountability and responsiveness in Europe has intensified. Journalists and scholars alike have argued that the largely pro-European elite is increasingly out of touch with their base. This became painfully evident through the rejections of the Constitutional Treaty in popular referendums in France and the Netherlands. While the integration process has motored full speed ahead, citizens throughout the European Union (EU) have become increasingly weary of the project (De Vries and Van Kersbergen 2007; Eichenberg and Dalton 2007). Although several studies demonstrate that political elites are actively monitoring their constituents (Carrubba 200r; Steenbergen et al. 2007), we witness a Europe that is divided: on average political elites have been much more in favor of European integration than their citizens (Hooghe 2003). 
The lack of electoral competition on European integration has characterized European Parliament (EP) elections ever since they were introduced in 1979 (Reif and Schmitt 1980; Schmitt 2005). This chapter explores the resulting mismatch in policy preferences between voters and their representatives after the most recent EP elections, which were held in June 2009. The main questions are whether there is still limited policy congruence with respect to European integration between citizens and their representatives, and how the apparent lack of policy congruence can be explained. The first explanation is that voters do not voice their opinions about European integration when they cast their vote - neither in elections for the European Parliament (EP) nor in national elections - but base their choice primarily on other considerations (Tillman 2004; De Vries 2007). The second explanation concerns the supply side of electoral politics, that is, the policy packages that political parties offer to voters. If among political elites there is consensus about the future of European integration, it becomes difficult for voters to express their policy preferences at the polls. Have voters been offered meaningful choices in the 2009 EP elections?

Anyone familiar with the work of Thomassen (1991, 2009c; Schmitt and Thomassen 1999) will see that these two explanations link up with the Responsible Party Model of political representation. This model sets out the conditions under which citizen preferences will be reflected by government policy: (I) there must be different parties with different programs, (2) parties must be sufficiently coherent to be able to implement policy, and (3) voters are required to vote for the party that is closest to their own policy preferences (Thomassen and Schmitt 1999c: 15-16; see also Pierce 1999). In this chapter we focus on the first and third condition and assess the quality of democracy in the European Union by examining party positioning and vote choice in the $2009 \mathrm{EP}$ elections, as well as in the latest national elections preceding these European elections.

To study the quality of democracy in the EU, we employ the concept of 'voting correctly', which was introduced by Lau and Redlawsk (1997, 2006). Whereas this concept was originally developed and tested in an experimental setting, it can also be applied to study voting in real elections. Indeed, Lau et al. (2008) used election survey data to study the quality of the vote decision in American presidential elections. Perceived policy congruence between voters and candidates was a key element of their analysis of correct voting, albeit it was not the only element. So in that sense our approach deviates from their work, as we will solely focus on policy congruence and thus neglect factors such as party identification or candidate images. We will elaborate on the reasons for doing so later in this chapter.

Note that in this chapter we adopt a rather narrow definition of democratic quality, namely one in which policy congruence is considered the ultimate purpose of elections (cf. Powell 2000) and hence responsiveness is put central. There is clearly more to democracy than what we focus on here (see e.g. Dahl I989). Hence in this chapter we do not assess democratic quality in the EU in full, but merely focus on the quality of electoral choice by focusing on policy preferences. ${ }^{1}$ But whatever 
view of democracy one would adhere, policy congruence is likely to be an important part of it. Indeed, responsiveness has been put forward as the single most important element of democratic quality (Diamond and Morlino 2005).

In the following sections, this chapter first discusses the two electoral channels in which voters may express their policy preferences: national elections and EP elections. Next, we elaborate on the idea of correct voting as an indicator of democratic quality. We then present some expectations about the ability of voters to make correct voting decisions in terms of two dimensions of political conflict: left/right and European integration. Having outlined the theoretical foundations, we proceed with the empirical analysis using data from the European Election Study 2009 about the fifteen oldest member states of the EU. We conclude by summarizing our findings and discussing some of its implications.

\subsection{Policy representation in the EU: two electoral channels}

One of the central claims of the discussion regarding the democratic deficit is the inability of voters to express their views on EU affairs. Within the context of a multi-level Europe, voters wishing to express their preferences regarding European integration in order to influence political elites are presented with two electoral channels: the intergovernmental channel (i.e. national parliamentary elections) and the supranational channel (i.e. European Parliament elections) (Beetham and Lord I998; Thomassen and Schmitt I999c). In national elections voters authorize and hold accountable their national representatives, who in turn shape the course of integration in the European Council and the Council of Ministers. In European elections voters can influence the partisan composition of the EP, which decisionmaking powers have increased rapidly over the two decades since the introduction of co-decision making.

Several scholars have emphasized that citizens fail to express their policy views on European integration in European Parliament (EP) elections, as these constitute 'second order national elections' (Reif and Schmitt I980; Van der Eijk and Franklin I996; Schmitt 2005). However, the real problem is arguably that citizens do not consider their opinions about European integration when voting in national elections. After all, the integration process is only partly shaped by supranational structures, such as the European Parliament. It is primarily in the hands of national political leaders that reach agreements through intergovernmental structures and that are accountable for their European activities in national elections (Thomassen and Schmitt I999a; Mair 2005). In practice the system of representation appears to not function properly, as voters do not express their EU preferences in either of these channels. EP elections "are fought primarily on the basis of national political concerns" (Franklin and Van der Eijk 1996: 7), while national elections are characterized by a "lack of inter-party policy differences on European matters (which) 
makes it difficult for parties to fight elections on European issues" (Van der Eijk and Franklin 1996: 369 ). Consequently, neither in their choice of national political leadership nor in their choice of members of the EP are voters able to make their preferences regarding European integration heard and democratically control the integration process.

The consequence of the missing linkage is that representatives may hold different opinions on European integration than their constituents. This has indeed been found. Thomassen and Schmitt (1999b), for example, compared the policy preferences of the voters in the 1994 European Parliament elections with those of the MEPs they elected. With respect to the process of European integration, which was captured by the issues of national borders and a single European currency, they observed clear differences: "Regarding both the abolishment of national borders and a common European currency, we find a wide discrepancy between preferences of voters and the positions of their representatives in the European Parliament. (...) Almost half of the Meps have no reservations about continuing to do away with national borders. There is far less enthusiasm among the mass public. Not more than one in five EU citizens supports open borders without any reservations. (...) In the case of the common European currency, the distance between voters and MEPS is even larger. Whereas more than $60 \%$ of the MEPs take the most outspoken position in the direction of a new common European currency, less than $20 \%$ of the voters do so" (Thomassen and Schmitt 1999b: 192-195). These figures illustrate that political elites hold more favorable attitudes toward European integration than their citizens. This suggests that the system of political representation as employed in the European Union has failed to establish policy congruence on this important dimension of political conflict.

More than a decade after the aforementioned conclusions were drawn, however, much has changed. More specifically, there is increasing evidence of the impact of $\mathrm{EU}$ attitudes on vote choice in national elections - a process referred to as $E U$ issue voting (De Vries 2007; see also Evans 1999; Gabel 2000; Tillman 2004). Consequently, at least in some countries an 'electoral connection' between national and European politics seems to be emerging (Carrubba 20or). These findings of increased Eu issue voting in the intergovernmental channel are not surprising. Several authors have argued that it is more rational for voters seeking a voice in the integration process to do so via national elections than via EP elections (Gabel 2000; Mair 2005, 2007). Thomassen and Schmitt (1999a) adequately identified this paradox: "Formal decisions on a further transfer of sovereignty from the national to the European level are subject to the intergovernmental regime of European decision-making. They need the consent of national governments and are, at least in principle, under the control of national parliaments and national electorates. Therefore, the interesting paradox is that what usually are called European issues are basically national issues. As far as the existing party system fails to offer a meaningful choice to voters, this is a problem at the national rather than the European level" (Thomassen and Schmitt 1999a: 259; emphasis in original). This means that for the 
study of political representation in the European Union it is important to conduct analyses at the level of individual member states, in addition to the study of supranational structures such as the EP. Indeed, nationally elected members of parliament are able to influence - or at least comment - on EU legislation, although their influence varies greatly among the member states (see Raunio 1999). Moreover, the Lisbon Treaty has strengthened the role of national parliaments in the scrutiny of EU policies. So, paradoxically, expressing policy preferences on European integration makes more sense in national elections than in EP elections (Mair 2005, 2007; Mair and Thomassen 2010).

\subsection{Voting correctly and the quality of democracy}

The simplest way for voters to ensure that their opinions about European integration are heard, is by selecting representatives that hold similar policy views and doing so in European as well as national parliamentary elections. We study the extent to which voters display such behavior by employing the notion of 'voting correctly' (cf. Lau and Redlawsk 1997, 2006). The notion of a correct vote refers to a vote that "is the same as the choice that would have been made under conditions of full information" (Lau and Redlawsk 2006: 75). This definition resembles Dahl's (I989: I80-18I) notion of a 'real'vote: "a person's interest or good is whatever a person would choose with the fullest attainable understanding of the experiences resulting from that choice and its most relevant alternatives."

The pivotal question, then, becomes: what does 'fully informed' mean? In Lau and Redlawsk's ( 1997,2006$)$ model 'fully informed' relates to all information available in the campaign. We, however, employ a somewhat different use of the term. In our view in the context of the Eu 'fully informed' is best defined as holding accurate views regarding the conflict dimensions that characterize political contestation at the European level, as well as the positions of the competing political parties in terms of each dimension. Furthermore, we assume that contestation at the European level is best characterized in terms of two dimensions: left vs. right and national sovereignty vs. European integration (cf. Steenbergen and Marks 2004; Hix et al. 2006; Schmitt and Thomassen 2009). ${ }^{2}$ We thus focus on the degree to which voters vote correctly when it comes to their preferences in terms of these two dimensions of political conflict.

The conceptualization of voting correctly in this study deviates from how the concept was employed in the experimental setting, where an information processing perspective was adopted. The basis for comparison was the vote that would have been cast with awareness of all pieces of information about candidates that were available, although these had not all become visible in the experiment. In the real world one could also focus on information available about parties or candidates, and for example base the analysis on an analysis of information available in the 
media during the election campaign. In our view, however, a better approach is to ground the criteria for assessing the correctness of a vote in (normative) democratic theory. Our approach is thus to put policy congruence central, building on the idea that the key function of elections is to give citizens influence over political leaders in terms of policy (cf. Powell 2000) through a system of political representation (Pitkin 1967). Although this approach differs from the one in the experimental setting, it resembles - at least partly - the approach adopted by Lau et al. (2008) when focusing on actual presidential elections.

The conceptualization influences the measurement adopted. In their work, Lau and Redlawsk (1997, 2006) provide two measures of voting correctly. The first is based on experimental data. In a controlled experimental setting, subjects were provided with complete information about mock candidates in a simulated election after they had voted. The vote of those participants who indicated they would not have changed their vote in light of this new information were classified as correct (Lau and Redlawsk 1997: 588-589). In an experimental setting correct voting may be approached in this way, but in the real world applying this method is virtually impossible. Lau and Redlawsk $(1997,2006)$ therefore provide another measure, which builds on the presumption that voters will never be fully informed. This measure uses the evaluation of voters' own, naive information-gathering strategy in order to find out if they would vote differently if the same criteria of judgement (i.e. issue stances, group endorsements and candidate evaluations) are applied to all candidates/parties.

If we combine the above considerations, a correct vote can be viewed as a vote that builds on information about all parties/candidates on all relevant dimensions of judgement, while putting equal weight on each dimension for all parties/candidates. If we assume that influence over policy is the purpose of elections (cf. Downs 1957; Powell 2000), and if we further assume that in the European Union political contestation takes place on two separate dimensions of conflict, this can be translated into the use of the shortest distance hypothesis in a two-dimensional political space (cf. Downs 1957; Enelow and Hinich 1984). The idea that this is the core of what may be considered 'the right way to vote' is of course not new and brings us back to the third element of the Responsible Party Model. To deepen our understanding, however, it is crucial to not just examine voting correctly in terms of the political space comprising both dimensions, but also analyze representation in terms of each individual dimension. This enables us to provide a more nuanced picture of the quality of representation and potential biases.

\subsection{Hypotheses}

This brings us to the expectations for the analysis. As noted above, one problem regarding representation on EU matters is that voters' choices at the polls are not strongly shaped by their opinions about European integration. Because the ideo- 
logical division between left and right is widely conceived as the dominant dimension of conflict in national politics (Pierce 1999) as well as European Union politics (Schmitt and Thomassen 1999, 2009), we expect that voting correctly in terms of left/right occurs more frequently than on European integration. Furthermore, because the integration process is shaped primarily through intergovernmental structures, we hypothesize that voting correctly in terms of European integration occurs more frequently in national parliamentary elections than in EP elections. So we formulate two hypotheses about voting correctly at the individual level:

\section{$\left(H_{1}\right)$ The level of voting correctly is higher in terms of left/right than in terms of European integration.}

\section{$\left(\mathrm{H}_{2}\right)$ The level of voting correctly in terms of European integration is higher in national parliamentary elections than in EP elections.}

It is important to bear in mind that the various EU member states have very different political context characteristics. These may affect the extent of correct voting within each country. Lau and Redlawsk (2006: 22) developed a model explaining the way in which the political environment influences the degree to which voters get it right. In keeping with Lau and Redlawsk (2006: 84), we focus on several macro-level hypotheses relating to the choice set, diversity of party positions and aggregate levels of $\mathrm{EU}$ support. We formulate these hypotheses with respect to the European integration dimension, because here deficiencies appear to be most serious.

The first hypothesis about country level differences relates to the size of the choice set, that is, the number of parties in the respective election. We expect higher levels of correct voting when there are fewer alternatives in the choice set. One reason is voters' cognitive constraints: It is easier to have knowledge about few parties than about many parties. The second reason is methodological: If voters would cast their vote at random, the chances that they would have voted for the party closest to them is simply higher with a lower number of parties. The next hypothesis relates to the distinctiveness of issue positions of political parties. The idea is that the easier it is for voters to distinguish between issue positions of political parties, the higher the likelihood of correct voting. This means that we expect that in member states where parties have more distinct positions on European integration, voters will more often choose parties that are closest to their own Eu preferences. ${ }^{3}$ Finally, it is sensible to also focus on the aggregate level of support for European integration in a country. Since the mid I99os political elites on average have been much more supportive of the European project than the mass public (Hooghe 2003). As a result, in countries with many harsh critics of European integration, voters will find it more difficult to vote correctly in terms of European integration, as party positions match badly with their own views. So we have three hypotheses concerning the amount of correct voting at the level of member states: 
( $\left.H_{3}\right)$ The smaller the choice set of political parties in a country, the higher the extent of correct voting in terms of European integration.

( $\left.\mathrm{H}_{4}\right)$ The more distinct the positions of political parties on European integration in a country, the higher the likelihood of correct voting in terms of European integration.

( $\left.\mathrm{H}_{5}\right)$ The more extensive the support for European integration in a country, the higher the likelihood of correct voting in terms of European integration.

\subsection{Data and method}

To measure and analyze correct voting, we rely on the European Election Study (EES) data from 2009. ${ }^{4}$ The EEs has the advantage that it allows for a comparison of correct voting in terms of left/right as well as European integration in the same way for a large number of countries. Because the 12 member states that most recently joined the EU have such a different position compared to the I5 older member states, we only focus on the latter.

The EEs 2009 questionnaire not only includes questions about vote choice in the EP elections in June 2009, but also asks respondents for which party they had voted in the latest national elections. The survey furthermore contains virtually identical measures for left/right and European integration. Regarding left/right, respondents are asked to indicate their political views by choosing the number between o and Io, where o means left and Io means right, that best represents their position. Using the same scale, they are asked to indicate what number best represents the position of several political parties. In the same vein, respondents are asked to place their own views as well as those of the political parties on scale concerning European integration. In this case the end-points are that European unification has already gone too far (o) and that it should be pushed further (Iо). We limit our analysis to parties that obtained at least one seat in the EP, thus neglecting very small parties that were sometimes also included in the survey. ${ }^{5}$

By answering these questions voters indicate, albeit indirectly, how similar they perceive their own political views as compared to the positions of the various political parties. We employ a simple measure as indicator of policy congruence in terms of either dimension, namely the distance between a voter's position and the perceived position of a party. Voting correctly is defined as voting for the party (or one of the parties) that is perceived closest in the two-dimensional space, which combines left/right ideology and European integration (Euclidean distance). This procedure matches the shortest distance hypothesis in Downs' (1957) conception of rational voting (see also Enelow and Hinich I984). ${ }^{6}$ In the case of ties (two or more parties equally close) a vote for any of them is considered a correct vote. 
One might argue that this measure fails to take into account the bias resulting from inaccurate perceptions of parties' positions on both scales and that the respondents' scores should be replaced by externally validated party positions; for example, the mean score awarded by all voters. Such a procedure would only make sense, however, if voters use the scale in an identical manner. The validity of this assumption is questionable. In particular with respect to left/right, respondents may interpret the labels differently. Indeed, Pellikaan (2010) found that in the Netherlands religious and secular voters have different views on the meaning of 'right' and consequently position particular parties differently. For that reason, we avoid such an alternative procedure and use respondents' own perception of party positions. To the extent that this affects our results, it implies that we most likely overestimate the degree of correct voting. ${ }^{7}$

Note that we conceive of both dimensions as making up one 'political space' and hence analyze voting correctly on the basis of measures indicating policy congruence on both dimensions simultaneously. To be able to study the quality of political representation in a more nuanced way, we also create measures that indicate whether individuals voted correctly if one would either only focus on left/right ideology or only focus on European integration.

\subsection{Results}

\subsubsection{Policy preferences of voters and parties}

Before we turn to the analysis of the extent of correct voting, let us first provide an overview of voters' and parties' positions on both dimensions of political conflict. Figure II.I provides an overview of voters' left/right positions across the $15 \mathrm{EU}$ member states. To enhance clarity of presentation, we rescaled the continuum to three categories: left-wing (o-3), center (4-6), and right-wing (7-10). Figure II.2 shows in a comparable way voters' stances towards European integration. We rescaled the corresponding survey item into three categories: 'pro European integration' (7-10), 'anti European integration' (o-3) and 'intermediate position' (4-6).

These figures provide several important pieces of information. Firstly, in the EU as a whole, in terms of both left/right and European integration, voters are fairly evenly spread across the three categories. This means that left-wing voters and rightwing voters are more or less in balance, and so are those in favor and those against European integration. Secondly, the figures show extensive variation across countries. These differences are most pronounced with respect to European integration. For example, in some countries, like Spain or Greece, voters are more often in favor of further European integration, whereas in other countries, like Austria or Finland, voters are more wary. Thirdly, there is only one member state where a majority of citizens favors further integration (i.e. Greece). In all other countries the support figure falls below the 50 percent mark. Moreover, in four member states (i.e. Aus- 
Figure 11.1 Citizens' ideological Left-Right position

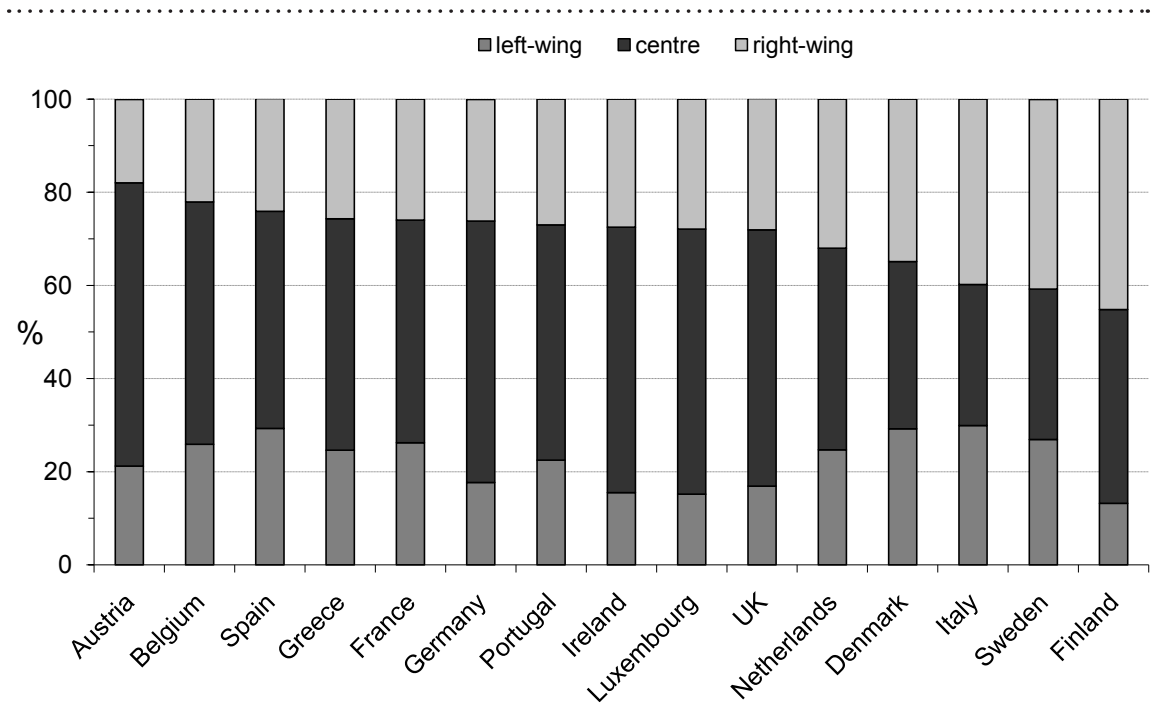

Source: European Election Study (EES), 2009

Figure 11.2 Citizens' support for European integration

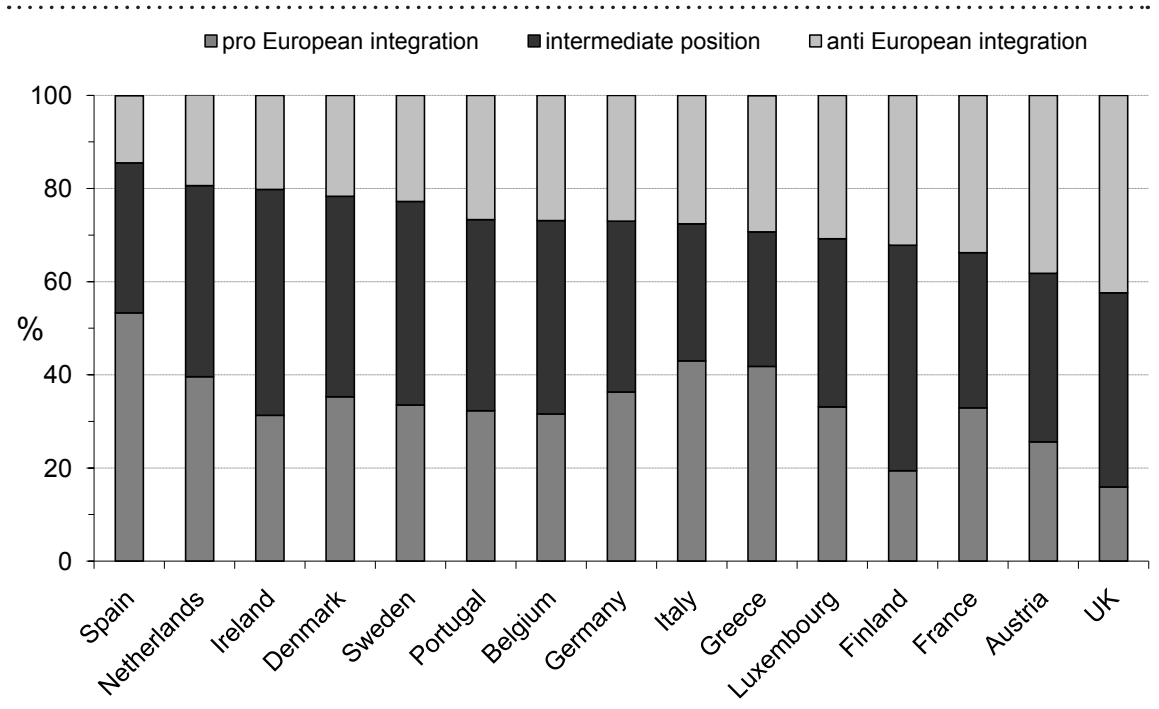

Source: EES 2009

tria, Finland, Sweden and United Kingdom) citizens who feel that integration has already gone too far outnumber citizens who favor integration to move ahead. 
Figure 11.3 Political parties' positions on Left-Right ideology (horizontal) and European integration (vertical)
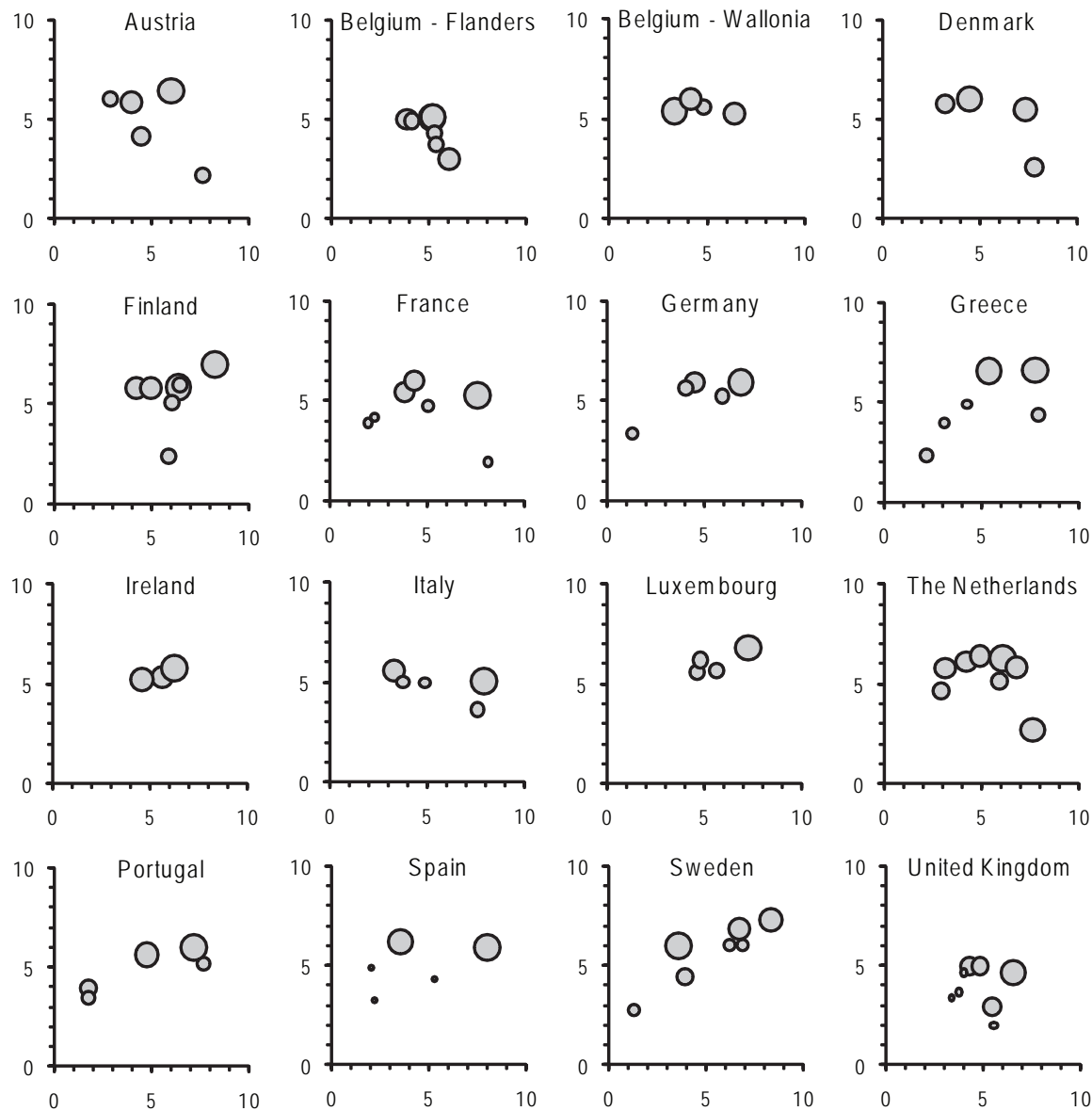

Note: Left-right (horizontal): 0 means 'left' and 10 means 'right'. European integration (vertical): 0 means 'anti European integration' and 10 means 'pro European integration'. The size of the dots increases with party size (within-country comparisons).

Source: EES 2009

How are parties positioned on both scales? Figure II.3 plots parties' positions on European integration against their left/right placements for each country. The figure also indicates the size of the parties: the size of the dots varies in accordance with the number of seats obtained in the $2009 \mathrm{EP}$ elections. ${ }^{8}$ We determined the position of a party by calculating the mean of respondents' perceived position on both scales. One major advantage of this procedure is that party positions are esti- 
mated on the same scale as voter positions. In order to ensure the validity of these voter-based measurements, we cross-validated them with expert judgements. ${ }^{9}$

The graphs enable us to make a number of observations. Firstly, they demonstrate that there are substantial differences between the extent to which parties are spread across both dimensions. With respect to left/right the general pattern is that parties are fairly spread across the continuum, albeit there are differences between countries (average range equals 5.5; average standard deviation equals 2.0). With respect to European integration there are also differences between parties, but these are less pronounced (average range equals 3.6; average standard deviation equals I.3). In all but two member states party positions range more in terms of left/right than in terms of European integration (the exceptions are the United Kingdom and Ireland, which have identical range for both dimensions).

Secondly, the figures reveal that there is no clear and simple relationship between the policy views of political parties on European integration and left/right ideology. In some countries the strongest opposition to the European project is voiced by right-wing parties (i.e. Austria, Denmark, France and the Netherlands), whereas in other countries the opposition is voiced on the left-wing (i.e. Germany, Greece, Portugal and Sweden). Finland and the United Kingdom are the only countries in which a party associated with opposition to European integration is positioned in the center of the left/right continuum. Note that this is the expected position for a single issue party focusing on national sovereignty, such as the $\mathrm{UK}$ Independence Party. The graphs also suggest that in some countries it is virtually impossible for citizens to voice discontent on European integration, since there is no party in the Euroskeptic area of the graphs (i.e. Ireland and Luxembourg).

Thirdly, if we take party size into account, it becomes clear that parties with relatively negative attitudes toward European integration are mostly small parties. The only exception is the Netherlands, where the recently established Freedom Party (PVv) of Geert Wilders became the second largest party in the 2009 EP elections. The positions of the large parties with respect to European integration tend to be fairly close to the midpoint of the scale - mostly slightly above and hence expressing a mild pro-European integration stance. The graphs also reveal that parties with a strong pro-European attitude are a rarity. Indeed, the Swedish Moderate Party and the Finnish National Coalition Party are the only parties that received an average score of at least 7.0. This indicates that if there are problems at the supply side, these apply as much for 'EU-phoria' as for 'EU-phobia.'

These results partly echo findings reported for previous EP elections, in which opposition towards the European project was also strongest among smaller parties, especially those on the extremes of the left/right dimension (Hooghe et al. 2002; Schmitt and Thomassen 2009). However, the country-level analyses also show that the curvilinear relationship between parties' positions on left/right and European integration for the $\mathrm{EU}$ as a whole (the so-called 'inverted U-curve' or 'horseshoe pattern'), does not adequately describe the political landscape of individual countries. Indeed, there is not a single country among these 15 member states in which 
strong Euroskepticism is expressed by both the left and the right. This means that voters wishing to express sentiments against European integration typically can either only turn to a small party on the far left, or only turn to a small party on the far right. Given the fact that left/right ideology strongly shapes party choice (Van der Eijk and Franklin 2006), the supply side of the electoral competition makes it rather difficult to establish accurate representation on the European integration dimension.

\subsubsection{Voting correctly across the 15 oldest EU member states}

We now turn to the levels of correct voting and the quality of political representation. How well are voters able to translate their perceptions about political parties' stands on both dimensions into a correct vote, that is, vote for the party closest in the two-dimensional space? Figure II. 4 provides an overview of the extent to which voters were getting it right in the 2009 European Parliament elections and thus reports the percentage of respondents that voted correctly. The figure also indicates to what extent vote choices matched the shortest distance hypothesis when applied to either left/right or European integration as a single dimension.

The general pattern across the 15 member states is that correct voting in terms of left/right occurred more frequently than correct voting in terms of the two-dimensional framework or in terms of European integration. Across the $\mathrm{EU}$ in terms of left/right on average 60 percent of the voters appeared to get it right. In terms of European integration the figure is somewhat lower, namely $5^{\mathrm{I}}$ percent. The figures for the two-dimensional space take an intermediate position at 56 percent. These findings support our first hypothesis $(\mathrm{HI})$ : correct voting occurred more often in terms of left/right than in terms of European integration.

Additional analyses (not reported here) indicate that only about one out of three voters cast their vote for a party that was closest on both dimensions. When interpreting this figure, one should realize that for many voters it may be logically impossible to vote for a party that represents them better than any other party on both individual dimensions simultaneously. Indeed, across the EU-I5 on average only 55 per cent of the voters were, given the positions of themselves and the competing parties, able to choose a party that provided the best match on both individual dimensions. In other words, almost half of the electorate is forced to choose between the best match on left/right or the best match on European integration.

Earlier in this chapter we argued that citizens wishing to influence European integration should not care most about EP elections, but about national elections. Hence, we hypothesized that correct voting in terms of European integration occured more frequently in national elections than in EP elections. However, our additional analysis of correct voting in national elections (not reported) does not confirm this expectation. In fact, on average the scores are 2 percent lower in national elections than in EP elections. So the second hypothesis $\left(\mathrm{H}_{2}\right)$ is not confirmed. Correct voting occurs as often in national elections as in EP elections. ${ }^{10}$ 
Figure 11.4 Percentage of voters who voted correctly

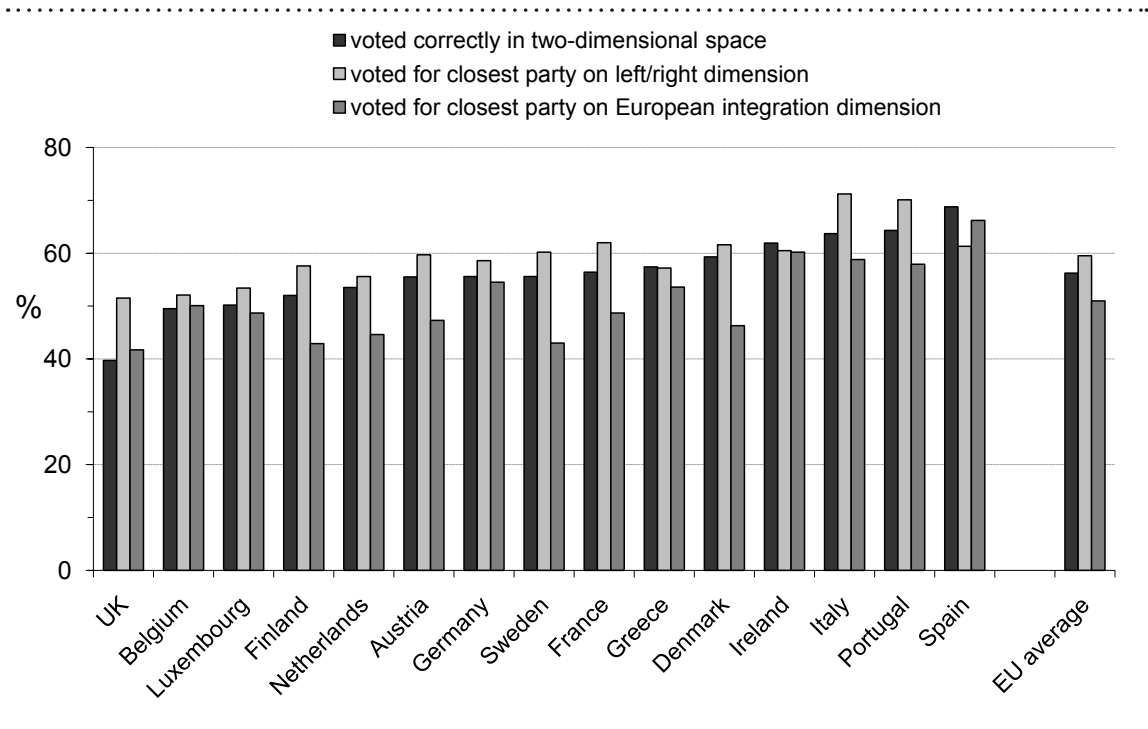

Source: EES 2009

\subsubsection{Explaining country differences in correct voting}

Variation exists across countries in the ability to which voters get it right when it comes to their left/right and European integration preferences. We explore these differences for the European integration dimension (where the level of correct voting is lowest) and focus on voting in the EP elections. How can we make sense of the cross-national variation in correct voting?

According to our third hypothesis $\left(\mathrm{H}_{3}\right)$ we expect more correct voting as the number of alternatives in the choice set decreases. To address this matter systematically, we calculated the correlation between the amount of correct voting on European integration in percent and the number of political parties in the European Parliament. ${ }^{11}$ We indeed find a negative relationship between the number of choice options and the extent to which voters choose the party that best represents their EU interests $(r=-.72, \mathrm{p}<0 . \mathrm{OI}$, one tailed).

The second explanatory factor relates to the meaningfulness of the choices available to voters. We hypothesized higher levels of correct voting when the positions that political parties take on European integration are more distinctive $\left(\mathrm{H}_{4}\right)$. We use the standard deviation of party positions on the European integration scale as an indicator for distinctiveness. The results provide no evidence for the hypothesized effect. There is no statistically significant relationship, while the sign is in the other direction than hypothesized $(r=-.42, \mathrm{p}=.06$, two-tailed $){ }^{12}$ Thus, we find no empirical evidence supporting the fourth hypothesis. 
The final factor that we consider is the average level of support for European integration. We expect that the more extensive the support for European integration in a country, the higher the likelihood of correct voting in terms of this dimension $\left(\mathrm{H}_{5}\right)$. We analyze this with a measure that equals the percentage of respondents who positioned themselves on positions 7 to Io on the corresponding survey item. The results support the idea that correct voting on European integration is positively related to general levels of support for European integration among voters $(r=.67, \mathrm{p}<$. oI, one-tailed). So in countries where relatively many citizens support European integration, voters are indeed more likely to choose a party that represents their view on this dimension of conflict.

If we combine the latter factor with size of the choice set in a single regression model to predict the amount of correct voting in a country, the explained variance $\left(R^{2}\right)$ equals 82 percent. The level of aggregate support for European integration and the number of choice options in the election appear to be key factors for explaining cross-national variation in correct voting on this dimension of conflict.

\subsubsection{Biases in representation at the individual level}

The findings suggest that slightly more than half of the Eu citizens in the Western member states voted in line with their policy preferences, while the figures for leftright and European integration as single dimensions do not deviate much. This means that at the individual level the quality of representation is presumably not optimal. Moreover, even for the majority who voted correctly the question arises whether the party they supported has identical policy views, or whether voters were in a sense forced - by the supply in policy packages provided to them - to select parties that hold different views. We therefore examine for those who voted correctly, as well as those who did not vote correctly, whether they perceived the party they voted for as holding identical policy views as oneself or not; and if differences between party and oneself were perceived, whether voters cast their vote for a party that was considered more left-wing or more right-wing, and more Eurosceptic or less Eurosceptic, than oneself. We again focus on the $2009 \mathrm{EP}$ elections.

Table II.I provides an overview of the types of representation biases associated with voters' party choice. Across the 15 member states on average 60 percent voted for a party that they perceived to take an identical position on the left/right dimension. The other voters opted slightly more often for a party they perceived as more right-wing than oneself than for a more left-wing party. The differences are limited, though, and hence in terms of left/right voters who voted correctly were collectively represented fairly accurately.

The second group of voters (i.e. those who voted incorrectly and thus supported a party that they did not consider closest on the left/right dimension) display a clear bias. These voters were about twice as likely to vote for a more right-wing party than a more left-wing party. If we combine respondents who voted correctly and who voted incorrectly, the resulting bias on average equals I7 percent (this bias is calculated as the difference between the percentage voting for a party more right- 
Table 11.1 Percentage of voters who voted for parties that were perceived as more left-wing or more right-wing than oneself

Au Bel Den Fin Fra Ger Gre Ire Ita lux Net Por Spa Swe UK EU-15 average

Voters who voted correctly in terms of Left/Right

$\begin{array}{lrrrrrrrrrrrrrrrr}\text { More left } & 20 & 19 & 17 & 14 & 11 & 17 & 12 & 20 & 15 & 10 & 13 & 23 & 19 & 13 & 19 & 16 \\ \text { Similar } & 51 & 56 & 65 & 63 & 62 & 61 & 68 & 46 & 56 & 65 & 73 & 60 & 56 & 67 & 54 & 60 \\ \text { More right } & 28 & 25 & 18 & 23 & 27 & 22 & 20 & 33 & 29 & 25 & 14 & 17 & 25 & 20 & 27 & 24 \\ \text { Total } & 100 & 100 & 100 & 100 & 100 & 100 & 100 & 100 & 100 & 100 & 100 & 100 & 100 & 100 & 100 & 100 \\ N & 292 & 318 & 426 & 309 & 215 & 309 & 337 & 300 & 319 & 292 & 324 & 298 & 260 & 395 & 210 & \\ \text { Voters who did not vote correctly in terms of Left/Right } & & & & & & & & & & \\ \text { More left } & 46 & 37 & 39 & 34 & 37 & 28 & 31 & 20 & 35 & 27 & 44 & 48 & 16 & 43 & 32 & 34 \\ \text { More right } & 54 & 63 & 61 & 66 & 63 & 72 & 69 & 80 & 65 & 73 & 56 & 52 & 84 & 57 & 68 & 66 \\ \text { Total } & 100 & 100 & 100 & 100 & 100 & 100 & 100 & 100 & 100 & 100 & 100 & 100 & 100 & 100 & 100 & 100 \\ N & 197 & 292 & 265 & 227 & 132 & 218 & 252 & 196 & 129 & 255 & 259 & 127 & 164 & 267 & 198 & \end{array}$

$\begin{array}{lllllllllllllllll}\text { Bias to right } & 8 & 16 & 9 & 19 & 20 & 21 & 21 & 32 & 19 & 29 & 6 & -3 & 30 & 10 & 22 & 17\end{array}$

Source: EES 2009

Table 11.2 Percentage of voters who voted for parties that were perceived as more or less in favour of European integration than oneself

Au Bel Den Fin Fra Ger Gre lre Ita Lux Net Por Spa Swe UK EU-15 average

Voters who voted correctly in terms of European integration

$\begin{array}{lrrrrrrrrrrrrrrrr}\text { More pro EU } & 25 & 24 & 26 & 15 & 30 & 21 & 25 & 25 & 38 & 22 & 22 & 25 & 30 & 21 & 16 & 24 \\ \text { Equally } & 44 & 48 & 51 & 56 & 50 & 51 & 57 & 47 & 39 & 44 & 59 & 49 & 44 & 57 & 63 & 51 \\ \text { Less pro EU } & 31 & 28 & 23 & 29 & 20 & 27 & 18 & 29 & 23 & 34 & 19 & 26 & 25 & 23 & 20 & 25 \\ \text { Total } & 100 & 100 & 100 & 100 & 100 & 100 & 100 & 100 & 100 & 100 & 100 & 100 & 100 & 100 & 100 & 100 \\ N & 228 & 283 & 304 & 198 & 148 & 280 & 271 & 305 & 183 & 255 & 242 & 169 & 233 & 253 & 166 & \\ \text { Voters who did not vote correctly in terms of European integration } & & & & & & & & \\ \text { More pro EU } & 19 & 32 & 39 & 20 & 26 & 27 & 30 & 19 & 34 & 16 & 34 & 28 & 34 & 27 & 16 & 26 \\ \text { Less pro EU } & 81 & 68 & 61 & 80 & 74 & 73 & 70 & 81 & 66 & 84 & 66 & 72 & 66 & 73 & 84 & 73 \\ \text { Total } & 100 & 100 & 100 & 100 & 100 & 100 & 100 & 100 & 100 & 100 & 100 & 100 & 100 & 100 & 100 & 100 \\ N & 254 & 282 & 353 & 264 & 156 & 234 & 235 & 202 & 128 & 269 & 301 & 123 & 119 & 336 & 232 & \end{array}$

$\begin{array}{lllllllllllllllll}\text { Bias pro-EU } & 36 & 20 & 10 & 40 & 20 & 24 & 15 & 27 & 4 & 41 & 16 & 19 & 8 & 27 & 41 & 23\end{array}$ 
wing than oneself and the percentage voting for a party more left-wing). Apparently, voters who have to choose between a party on their right and a party on their left were more strongly inclined to choose a party on their right. The figure varies substantially across countries. For example, the bias in left/right is fairly strong in Spain and Luxembourg (3o percent), but virtually absent in Portugal and the Netherlands. As expected, this variation across countries is related to the number of parties $(r=-.5 \mathrm{I}, \mathrm{p}<.05$, one tailed). If there are more parties to choose from, there is less bias in terms of left/right.

Table II.2 presents a similar analysis for the European integration dimension. Individuals who voted correctly in terms of European integration in half of the cases did so for a party that took an identical policy position. The others split more or less evenly between parties that held a more or less favorable opinion about further integration. Furthermore, voters who did not 'get it right' mostly voted for parties that were less Euroskeptic. Those voting for parties with more favorable stands towards integration outnumbered those voting for parties less supportive of moving ahead with integration by three to one. The overall bias at the aggregate level exceeds that for left/right and amounts to 23 percent. Given the fact that parties that are skeptical about European integration are scarce, this finding is not surprising. This bias is exactly what can be expected on the basis of the positions of political parties on this dimension. We have also calculated the size of the bias for the previous EP elections, which were held in 2004, and obtained an identical outcome (23 percent). So the quality of representation has not improved in the latest EP elections (nor worsened). ${ }^{13}$

Again, there are substantial differences between countries. The bias is particularly strong in the United Kingdom, Austria and Finland (4o percent), whereas there is virtually no bias in Italy and Spain. For this variation across countries the number of parties is not relevant ( $\mathrm{r}=. \mathrm{oI}, \mathrm{p}=.98$, two-tailed). This can be understood on the basis of the fact that in terms of European integration there is less variation in party stances and major parties hardly ever opposed European integration so far (see Figure II.3). Another factor, however, does affect the country differences: the amount of aggregate support for European integration ( $\mathrm{r}=-.82, \mathrm{p}<$.or, one-tailed). So the bias is strongest in countries with little popular support for further European integration and this factor alone explains two thirds of the variance $\left(R^{2}=.66\right)$.

\subsection{Conclusions}

This study has assessed the health of political representation in the European Union by examining the success of voters in selecting a party that most accurately represents their policy preferences. The analysis focused on the two dimensions that characterize political contestation in the European Union - left/right ideology and European integration - and focused on Western Europe, i.e. the I5 oldest member states of the EU. In order to determine the quality of democratic representation we 
introduced the concept of voting correctly, i.e. are voters' actual votes the same as the choices they would have made if they would be aware of these dimensions of conflict and voted accordingly?

In all, our results on the basis of the European Election Study 2009 show that in terms of left/right, approximately six out of ten voters appear to be getting it right, while about five out of ten voters get it right when it comes to European integration. This confirmed our hypothesis that correct voting is more likely in terms of left/right than European integration. For a two-dimensional space comprising both dimensions the figure lies somewhere in between, suggesting that only slightly more than half of the electorates choose parties that best represent their policy preferences. There were no substantial differences between EP elections and national elections. The amount of correct voting varied across member states. We hypothesized this variation to be a function of choice set (number of parties) as well as the range in parties' Eu positions. The findings lend support for the former hypothesis, but not the latter. Furthermore, we observed, as expected, that correct voting was more likely in countries where voters' opinions were relatively positive (like, on average, those of political elites across the EU).

Those who did not vote correctly in terms of left/right relatively often chose parties that were perceived as more right-wing than themselves. The resulting bias in representation was negatively related to the number of parties that citizens could choose from. A larger bias exists when it comes to the European integration dimension. Here voters were relatively likely to vote for parties that were less Euroskeptic than themselves. This bias was strongest in countries where the public as a whole showed least support for European integration and appears to be caused by the fact that in virtually all I5 countries the main parties have not voiced opposition to European integration so far.

The findings of our analyses suggest that there are deficiencies in the quality of representation in the European Union. Furthermore, the findings point to two causes that are known from studies focusing on earlier EP elections. First, at the supply side political parties show limited variation in policy preferences concerning European integration, at least less than in terms of left/right. Furthermore, opposition to European integration is usually voiced by relatively small parties that are positioned either relatively far on the left or relatively far on the right. The combination of negative $\mathrm{EU}$ attitudes on the left and the right, which is known to characterize the EU as a whole (Hooghe et al. 2002; Schmitt and Thomassen 2009), is non-existent at the level of individual countries. This means that voters who wish to base their choice strongly on left/right ideology, often have no viable option to also express their EU sentiments.

Second, at the demand side we have shown that about half of the electorate seems to - consciously - vote for a party that does not best represent their views on European integration. Moreover, this group in particular appeared to comprise the voters that cause the bias. So the problem is not only that parties do not offer what voters want with respect to European integration. Also, voters do not pick the par- 
ties that best represent their policy views on this dimension of conflict. Low levels of ' $\mathrm{EU}$ issue voting' result in elected representatives failing to accurately represent their voters on this dimension.

Hence, this study suggests that a failing linkage exists between political elites and their voters regarding EU matters. As such, it need not be a surprise that when European integration matters are put up for referendum, citizens are not as enthusiastic as the politicians that represent them. These findings also constitute a 'warning-sign' for Europe's political leaders. What lies ahead when the integration process is pushed further, is likely to be met by increased popular backlash. Currently, many voters are willing to put their EU preferences on hold in EP elections and national elections, and knowingly vote for parties more favorable of European integration than they themselves are. However, as integration efforts increasingly encroach upon voters' everyday lives, this may not prove a stable equilibrium. In the process of consolidating previous integration efforts, of even taking further steps, political elites may otherwise experience the electoral costs of failing to represent their voters on European affairs.

\section{Acknowledgement}

Earlier versions of this chapter were presented at the Annual National Conference of the Midwest Political Science Association, Chicago, 3-6 April 2008, and the Annual Conference of the Dutch Political Science Association and Flemish Political Institute (Politicologenetmaal), Berg en Dal, The Netherlands, 29-30 May 2008. We are grateful to participants in these conferences, as well as colleagues in our departments, for their valuable comments.

\section{Notes}

I For broader views, we refer to other literature on the concept of democracy (Held 2006), the functions of democratic elections (Katz 1997), the notion of democratic quality (Diamond and Morlino 2005), and democratic quality in the EU (Majone 1996; Moravcsik 2002; Zweifel 2002; Crombez 2003; Follesdal and Hix 2006).

2 Note that many authors argue that next to left/right ideology the political space in Western Europe consists of a cultural dimension (Inglehart 1977; Flanagan 1987; Kitschelt I989; Inglehart et al. 1991; Hooghe et al. 2002; Kriesi et al. 2006). This second dimension of political contestation involves the divide between values, such as public order, national security and traditional life styles, and values, such as individual choice, political participation and environmental protection (Dalton 1996: 8I-82). For simplicity's sake we do not include this dimension as such in our analysis. The main reasons are that the EEs does not include adequate indicators for voter and party positions on this dimension, some of those issues have become incorporated in the words left and right, and this dimension 
shows overlap with the European integration dimension of conflict and hence including it would complicate the analysis.

3 Lau and Redlawsk (2006: 84) also introduced another macro-level factor: the balance of an electoral campaign. Coming from the us context, the researchers focus on the (material) resources available to each candidate. This is less useful in Western Europe, as material resources appear to play a less crucial role and thus are not suitable as a proxy for campaign attention.

4 Ees (2009), European Parliament Election Study 2009, Voter Study, Advance Release, 7 April 2oro. Data and documentation are available at http://www.piredeu.eu. See also Van Egmond et al. (2010).

5 Parties for which data on its issue stands are not available have been excluded from the analysis.

6 An alternative approach would be applying the directional theory of issue voting (Rabinowitz and Macdonald 1989; see also Aarts and Aardal in this volume). However, the underlying idea that respondents' answers to such survey questions indicate which of two sides on an issue they take, combined with the intensity of this preference, is not plausible for the left/right scale (Granberg and Gilljam 1997). Moreover, although intuitively the situation could be different for the survey item about European integration, also for this dimension of conflict doubts have been cast on the usefulness of the directional theory (Granberg and Gilljam 1997).

7 Future research may analyze the extent to which our results are biased due to the measures used. One possibility is to make use of the Candidate Survey of the PI REDEu project and use candidate placements to determine party positions. At the moment that we write this chapter, however, these data are not yet available.

8 The size of the dot corresponds with the number of seats obtained in the 2009 EP elections by that party as compared to the number of seats obtained by the largest party in that country.

9 We cross-validated the mean voter ratings in the by comparing identical measures from the European Election Study 2004 with expert judgements from the Chapel Hill Expert Survey (ches) from 2006 (Bakker et al. 2008). The mean scores from the EEs proved valid, as they correlated highly with the cHes data (Pearson's R amounts to .93 on the left/right and to .86 on the European integration scale; both correlations are significant at the $\mathrm{p}=0.00 \mathrm{I}$ level). Those who are surprised about such strong correlations are reminded that accurate estimates from a group do not require accurate estimates at the individual level. Mistakes can cancel each other out and hence at the aggregate level reasonable estimates of parties' positions can be obtained with this procedure (cf. Erikson et al. 2002; Surowiecki 2004).

Io The difference between the figures for both sorts of elections could be a methodological artefact resulting from the time interval between the moment the survey was conducted (around the EP elections) and the latest national elections (up to five years earlier). Indeed, slightly different outcomes are obtained if we use another measure of vote preference in national elections, namely a question that asks how individuals would vote "if there was a general election tomorrow." The correct voting figures for EP elections and national elec- 
tions then become virtually identical. The fact remains, though, that our second hypothesis is not supported by the data.

II The number of parties corresponds with the number of parties that obtained one or more seats in the European Parliament elections in 2009. Regional parties (e.g. Scottish Nationalist Party) have been excluded, because for a majority of the population such parties are not an option. For Belgium, the average number of parties in Flanders and Walloon has been taken.

I2 If we would use another measure (i.e. the range), the relationship becomes significant, but it is still in the 'wrong' direction ( $r=-.54, \mathrm{p}<.05$, two-tailed).

I3 The corresponding figure for left/right in the $2004 \mathrm{EP}$ elections equalled I2 percent, which suggests that the bias in terms of left/right has increased (to I7 percent in 2009). 